\title{
Dehydrogenation of ocimene by active carbon: artefact formation during headspace sampling from leaves of Phaseolus lunatus
}

\author{
Mesmin Mekem Sonwa, ${ }^{\mathrm{a}}$ Christian Kost, ${ }^{\mathrm{a}}$ Anja Biedermann, ${ }^{\mathrm{a}}$ Robert Wegener, \\ Stefan Schulz, ${ }^{b}$ and Wilhelm Boland ${ }^{\mathrm{a} *}$ \\ ${ }^{a}$ Department of Bioorganic Chemistry, Max Planck Institute for Chemical Ecology, Beutenberg \\ Campus, Hans-Knöll-Str. 8, D-07745 Jena, Germany \\ ${ }^{b}$ Department of Organic Chemistry, Technical University of Braunschweig, Hagenring 30, \\ D-38106 Braunschweig, Germany \\ E-mail: Boland@ice.mpg.de
}

\begin{abstract}
The blend of volatiles emitted from jasmonate-treated Lima bean (Phaseolus lunatus) leaves comprised two ocimene-derived artefacts that were only present, if the compounds were collected on active carbon traps. Identified were (3E,5E)-2,6-dimethyl-3,5,7-octatrien-2-ol (6) and (3E,5E)-2,6-dimethyl-1,3,5,7-octatetraene (5) resulting from oxidation of ocimene (2) by active carbon in presence of humid air. The catalytical capacity of the active carbon could be exploited for a rapid and efficient functionalization of ocimene to give the (3E,5E)-2-alkoxy3,5,7-octatrienes (14), (15), and (16) in methanol, ethanol, or isopropanol as solvents.
\end{abstract}

Keywords: Phaseolus lunatus, active carbon, induced volatiles, ocimene, closed-loop-stripping analysis (CLSA), SPME

\section{Introduction}

The Lima bean (Phaseolus lunatus) exhibits selective response patterns to different herbivores ${ }^{1}$ or chemical elicitors like jasmonic acid. ${ }^{2}$ The different blends of volatiles which are emitted upon herbivore feeding are generally believed to attract natural enemies of the herbivores and thereby function as an indirect plant defence. ${ }^{3,4}$ Thus, precise knowledge on the qualitative and quantitative composition of the volatile blends is essential for understanding multitrophic interactions. Analysing the volatile organic compounds emitted by the Lima bean after treatment with jasmonic acid (JA), we observed two rare monoterpenes that were only present in the volatile blend collected with the closed-loop-stripping method (CLSM) ${ }^{5}$ (see Table 1), yet were absent if volatiles were collected on polydimethylsiloxane-coated fibres with solid-phase- 
microextraction (SPME). ${ }^{6}$

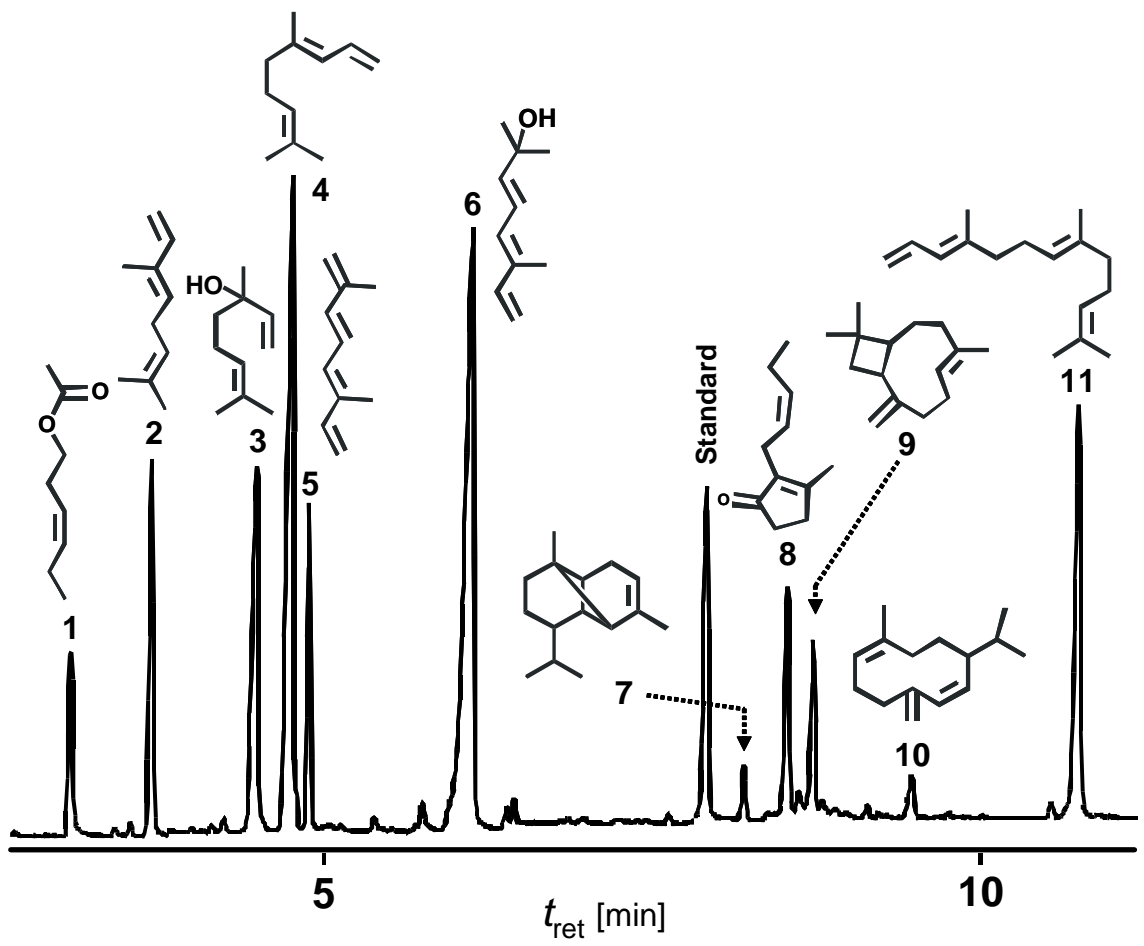

Figure 1. Gas chromatographic separation of volatiles collected from the gas phase around Lima bean leaves treated with jasmonic acid. Compounds were absorbed on charcoal traps ${ }^{5}$ and analyzed by GLC-MS after desorption with $\mathrm{CH}_{2} \mathrm{Cl}_{2}$. Despite of 5 and 6 all other compounds were identified previously. ${ }^{5,7}$

Table 1. Mean amount ( \pm SD) of 2, 5 and 6 released by three Lima bean plants after treatment with jasmonic acid $(1 \mathrm{mmol})$. Volatiles were collected with charcoal traps or SPME fibres for 24 h. The eluate of one charcoal trap was re-trapped by SPME for $30 \mathrm{~min}$. Area has been referenced to plant dry weight (DW)

\begin{tabular}{lccc}
\hline Sampling method & Mean area \pm SD (count seconds $10^{8} * \mathrm{~g} \mathrm{DW}^{-1}$ ) \\
\hline & $\mathbf{2}$ & $\mathbf{5}$ & $\mathbf{6}$ \\
Charcoal trap & $24 \pm 15$ & $2.9 \pm 1$ & $6.5 \pm 5$ \\
SPME fibre & $2.0 \pm 1$ & n.d. & n.d. \\
$\begin{array}{l}\text { Eluate of charcoal trap } \\
\text { re-trapped with SPME }\end{array}$ & 34.2 & 0.4 & 4.7 \\
\hline
\end{tabular}

n.d. $=$ not detected 
Trapping ocimene with commercial charcoal traps and subsequent analysis of the desorbed compounds with GC-MS again revealed the presence of 5 and $\mathbf{6}$, whereas simultaneous trapping of the same headspace with SPME did not result in the detection of these compounds. The two substances 5 and $\mathbf{6}$ have been previously identified in the headspace of hyacinth flowers where they could only be detected in headspace samples yet not in extracts or distillates of the same plant material. ${ }^{9}$

Furthermore, the substances could be clearly identified as artefacts derived from $(E)-\beta$ ocimene (2), which is formed in the presence of active charcoal. ${ }^{9}$ Here we report on this carbonmediated reaction that rapidly and stereo-selectively leads to a functionalisation of 1,3-dienes.

\section{Results and discussion}

\section{Active carbon catalysed oxidation of ocimene}

Active carbon is a well known support for noble metals, such as palladium and platinum. ${ }^{10}$ Coughlin et al. have reported redox reactions catalysed by carbon, halogenation and even polymerization. ${ }^{11}$ Active carbon is also known to catalyse the oxidation of fluorene as well as halogen exchange reactions. ${ }^{12}$ Makino et al. demonstrated that activated active carbon catalyses the conversion of physalin B into 25-hydroxyphysalin B under very mild conditions. ${ }^{13}$ Although the mode of action of active carbon has not yet been established, carbon-oxygen surface complexes have been postulated. Other reactions may be due to the acidic or alkaline nature of the carbon surface. ${ }^{12}$ Tomita et al. postulated free radicals as carbon surface active sites catalysing the reaction. $^{14}$

To clarify whether radicals play a role in the active carbon catalysed hydroxylation of ocimene, active carbon was either treated with the radical starter AIBN or with the radical scavenger BHT prior to the addition of ocimene. In both cases, no change was found in the catalytic activity of active carbon, suggesting that radicals are not involved in the oxidation process. Alternatively, oxygen-functionalized 1,4-quinonoid centres on the surface of active carbon have been recently discussed for the dehydrogenation of ethylbenzene to styrene. ${ }^{15,16}$ Accordingly, the initial step of the dehydrogenation of ocimene is the transfer of a hydride to a surface carbonyl (Scheme 1). 


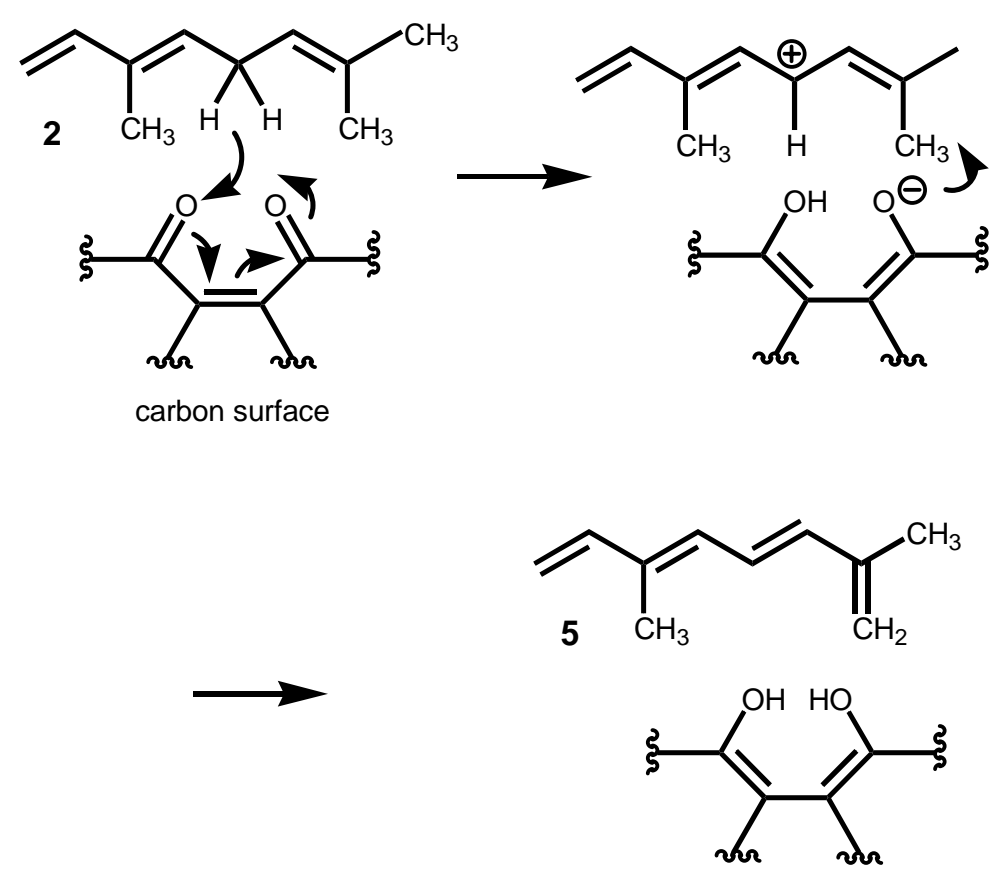

Scheme 1. Postulated mechanism of the dehydrogenation of ocimene by unsaturated 1,4diketone centres on the surface of active carbon; modified after ref. ${ }^{15}$ The proposed mechanism resembles dehydrogenation reactions mediated by DDQ. ${ }^{17}$

Subsequent loss of a proton from the resonance-stabilized cationic intermediate to the resulting phenolate anion completes the sequence and yields the tetraene 5. If a nucleophile is present, this could compete with the elimination and lead to functionalized octatrienes as shown in Scheme 2. The observation that the same dehydrogenation could be also achieved by $\mathrm{DDQ}^{17}$ by simply stirring of 1 eq. of ocimene in tetrachloromethane with 3 eq. of DDQ at r.t. suggests that the transformation may indeed follow the mechanistic model of Scheme 1. To verify this reaction course, moistened active carbon was stirred in hexane and oxygen was removed by passing argon through the suspension $(1 \mathrm{~h})$ followed by addition of ocimene (2). After $72 \mathrm{~h}$, GLC-MS analysis revealed, besides unreacted ocimene (30\%), the presence of the alcohol 6 (35\%) along with the tetraene $5(30 \%)$, demonstrating that the presence of active carbon is sufficient to achieve the reaction. In a more polar medium (acetone/water, access of air), the oxidation proceeded faster, and after $48 \mathrm{~h}$ most of $2(60 \%)$ was converted to the alcohol 6 and the hydrocarbon 5. Control experiments without active carbon did not result in oxidation of ocimene. Since the cationic intermediate of Scheme 1 principally allows a reaction with nucleophiles, we tested several alcohols as solvents and reactants (Scheme 2). 


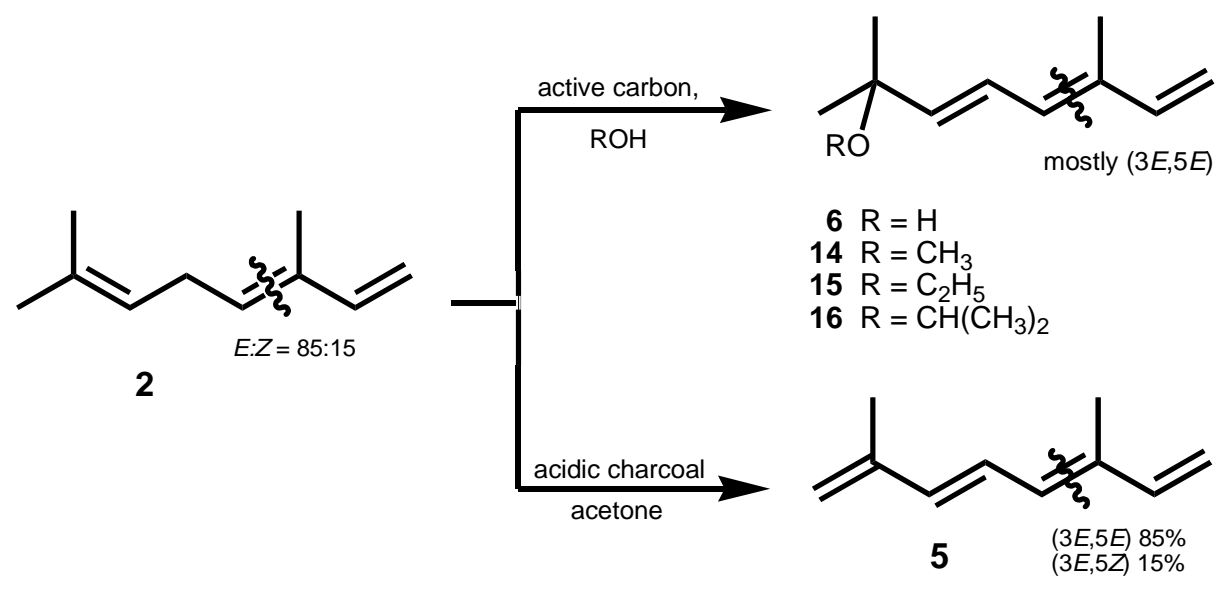

Scheme 2. Oxidative transformations of ocimene with active carbon.

In fact, simple stirring of ocimene with active carbon in methanol generated 2-methoxy-2,6dimethyl-octa-3,5,7-triene (14), known as a minor constituent of the essential oil of Narcissus geranium. ${ }^{18}$ Previous syntheses of $\mathbf{1 4}$ required lengthy multi-step procedures. ${ }^{18}$ The starting mixture of $(3 E, Z)$-ocimene showed a faster conversion of the $(3 E)$-isomer resulting in oxidation products with higher configurational purity than the educts. According to NMR, the new double bond was exclusively trans. A similar reaction was performed in ethanol and yielded (3Z,5E)-7ethoxy-3,7-dimethylocta-1,3,5-triene (15) with a non-optimized yield of $13 \%$ after $48 \mathrm{~h}$ and 18 $\%$ after $72 \mathrm{~h}$. In isopropanol (3Z,5E)-2-isopropoxy-2,6-dimethyl-octa-3,5-diene (16) was obtained albeit in low yield ( $5 \%$ after $48 \mathrm{~h}$ and $6 \%$ after $72 \mathrm{~h}$ ). In $t$-butanol only trace amounts of the corresponding $t$-butylether were detected (ca. $1 \%$ ), demonstrating that only primary and secondary alcohols can be used.

If the acidic character of the active carbon was increased by pre-treatment with nitric acid prior to use (acetone as solvent), ocimene was directly transformed to the hydrocarbon 5 . Scope and limitations of this novel and operationally simple, active carbon-mediated, functionalization of 1,3-dienes are currently investigated.

\section{Experimental Section}

General Procedures. ${ }^{1} \mathrm{H}$ and ${ }^{13} \mathrm{C}$ NMR: Bruker Avance 400 spectrometer (Bruker, D-76287 Rheinstetten, Karlsruhe, Germany). Chemical shifts of ${ }^{1} \mathrm{H}$ and ${ }^{13} \mathrm{C}$ NMR are given in ppm $(\delta)$ based on solvent peaks: $\mathrm{DCCl}_{3} 7.26 \mathrm{ppm}\left({ }^{1} \mathrm{H} \mathrm{NMR}\right)$ and $77.70 \mathrm{ppm}\left({ }^{13} \mathrm{C} \mathrm{NMR}\right) ; \mathrm{CD}_{3} \mathrm{OD} 3.31$ ppm ( ${ }^{1} \mathrm{H}$ NMR) and $49.00 \mathrm{ppm}\left({ }^{13} \mathrm{C} \mathrm{NMR}\right)$. GC-MS spectra were recorded on a Finnigan GCQ, equipped with an Alltech DB5 $(0.25 \mathrm{~mm}$ x $30 \mathrm{~m})$ column. Helium at $30 \mathrm{~cm} \mathrm{~min}^{-1}$ served as carrier gas. Compounds were eluted under programmed conditions starting from $40{ }^{\circ} \mathrm{C}$ (4 min) and then at $10{ }^{\circ} \mathrm{C} \mathrm{min}$ m $^{-1}$ to $200{ }^{\circ} \mathrm{C}$ followed $55^{\circ} \mathrm{C} \min ^{-1}$ to $280{ }^{\circ} \mathrm{C}(3 \mathrm{~min})$. Activated carbon was purchased from Aldrich, Cat.: 16,155-1, 82024 Taufkirchen, Germany). 
Plant material. Experiments using jasmonic acid-treatments were performed with Lima bean plants (Phaseolus lunatus; var. Jackson Wonder Bush). Seeds were obtained from Kelloggs Seed Inc., USA. Individual plants were grown from seeds in plastic pots $(\varnothing=5.5 \mathrm{~cm})$ with sterilized potting soil at $21-23{ }^{\circ} \mathrm{C}$ and $50-60 \%$ humidity using daylight fluorescent tubes at approximately $470 \mu \mathrm{E} \mathrm{m}^{-2} \mathrm{~s}^{-1}$ with a photophase of 14 hours.

\section{Induced biosynthesis of volatiles and collection of emitted compounds}

10- to 14-d-Old plantlets of $P$. lunatus with two fully developed primary leaves were cut with razor blades and immediately placed into glass vials containing an aqueous solution of jasmonic acid (4 $\mathrm{ml}$ of a $1 \mathrm{mmol}$ aqueous solution of jasmonic acid). The vials with the plants were transferred to 51 desiccators and the emitted volatiles collected over a period of $48 \mathrm{~h}$ with the closed loop stripping method (CLSA $\left.;{ }^{5}\right)$ using active carbon traps (1 mg of charcoal, CLSAFilter, Le Ruisseau de Montbrun, F-09550 Daumazan sur Arize, France). At the end of the collection period, the trapped volatiles were eluted from the active carbon by washing three times with $10 \mu \mathrm{l}$ of dichloromethane. 1-Bromodecane was used as an internal standard (400 $\mu \mathrm{g}$ $\mathrm{ml}^{-1}$ ). The collected samples were analysed by GLC-MS and indicated, besides other compounds shown in Figure 1, the presence of $\mathbf{5}$ and 6. Alternatively, volatiles were collected with SPME fibres coated with carboxen ${ }^{\mathrm{TM}}$-polydimethylsiloxane (Supelco/Aldrich, Cat.: 57318, D-82024 Taufkirchen, Germany) ${ }^{6}$. Subsequent thermal desorption from the fibre and GLC-MS analysis confirmed the presence of all compounds shown in Figure 1 except of the ocimene-derived artefacts 5 and 6. The observation that re-trapping an eluate of an active carbon trap measurement with SPME and analysing it with GLC-MS, lead to the compounds 5 and $\mathbf{6}$ suggested that both compounds originated from the first collection process using active carbon traps.

Active carbon catalyzed hydroxylation of ocimene to 2,6-dimethylocta-3,5,7-triene-2-ol (6). $30 \mathrm{mg}(0.22 \mathrm{mmol})$ ocimene (mixture of 3E,Z-isomers, ca. 85:15) was added to a suspension of active carbon $(0.5 \mathrm{~g})$ in $31 \mathrm{ml}$ acetone/water $(30: 1, \mathrm{v}: \mathrm{v})$ and the mixture was stirred at room temperature. After 48 hours, GC-MS analysis showed that $60 \%$ of ocimene (largely the (3E)isomer) was transformed. After 72 hours, the (3E)-isomer and ca. $50 \%$ of the (3Z)-isomer were hydroxylated. After $96 \mathrm{~h}$ both isomers were completely transformed. Following addition of water $(20 \mathrm{ml})$ the product was extracted with pentane $(3 \times 20 \mathrm{ml})$, concentrated in vacuo, and purified by chromatography on silica gel. Yield: $14 \mathrm{mg}(41 \%)$. The spectroscopic data were in agreement with literature data. ${ }^{17}$

\section{Functionalisation of ocimene, general procedure}

Activated carbon $(2.5 \mathrm{~g})$ was suspended with stirring in either methanol $(120 \mathrm{ml})$, ethanol or isopropanol $(415 \mathrm{ml})$ followed by addition of ocimene $(198 \mathrm{mg}$, mixture of $3 E / Z$ isomers, ca. $85: 15)$. After stirring at r.t. for $48 \mathrm{~h}$ or $72 \mathrm{~h}$ the reactions were stopped and the activated carbon 
was removed by filtration. GC-MS analysis demonstrated the formation of 2-methoxy-2,6dimethylocta-3,5,7-triene (14) from methanol, 2-ethoxy-2,6-dimethylocta-3,5,7-triene (15) from ethanol, and 2-isopropoxy-2,6-dimethylocta-3,5,7-triene (16) from isopropanol as solvent and nucleophile. For isolation of the ethers the solvents were removed under reduced pressure and the products purified by column chromatography. Owing to the high volatility of the ethers the removal of the rather large amounts of solvents resulted in low yields of isolated products.

Dehydrogenation of ocimene with acidic active carbon. $100 \mathrm{ml}$ of $66 \%$ nitric acid was added to $20 \mathrm{~g}$ of activated carbon and the mixture was stirred for 18 hours. Nitric acid was removed and the active carbon was washed with distilled water until the $\mathrm{pH}$ of the suspension of active carbon in water stabilized at 5.5. Water was removed and the active carbon was dried at $80^{\circ} \mathrm{C}$ for 16 hours. $20 \mathrm{mg}$ of the oxidized active carbon was used for the transformation of ocimene, following the same protocol as for untreated active carbon. After 24 hours GC-MS analysis revealed complete conversion of ocimene to the hydrocarbon 5 .

\section{Spectroscopic data}

(3E,5E)-2,6-Dimethyl-1,3,5,7-octatetraene (5). ${ }^{1} \mathrm{H} \mathrm{NMR}\left(\mathrm{CDCl}_{3}, 400 \mathrm{MHz}\right) \delta 6.55\left(\mathrm{dd}, 1 \mathrm{H}, J_{4,5}\right.$ $\left.=15.4 \mathrm{~Hz}, J_{4,5}=11.5 \mathrm{~Hz}, \mathrm{H}-4\right), 6.45\left(\mathrm{dd}, 1 \mathrm{H}, \mathrm{J}_{7,8 \mathrm{a}}=10.6 \mathrm{~Hz}, J_{7,8 b}=17.4 \mathrm{~Hz}, \mathrm{H}-7\right), 6.57(\mathrm{~d}, 1 \mathrm{H}$, H-5), 6.14 (d, 1H, H-5), 5.41 (d, 1H, H-8b), 5.04 (d, 1H, H-8a), 5.00 (s, 4H, H-1), 1.90 (d, 5H, $\left.\mathrm{CH}_{3}\right), 1.89\left(\mathrm{~s}, 5 \mathrm{H}, \mathrm{CH}_{3}\right) ;{ }^{13} \mathrm{C} \mathrm{NMR}\left(\mathrm{CDCl}_{3}, 100 \mathrm{MHz}\right) \delta 142.9(\mathrm{C}-4), 141.5(\mathrm{C}-7), 136.5(\mathrm{C}-3)$, 136.3 (C-6), 131.9 (C-5), 125.7 (C-4), 117.1 (C-1), 112.7 (C-8), $18.6\left(\mathrm{C}^{-}-\mathrm{CH}_{3}\right), 12.2\left(\mathrm{C} 2-\mathrm{CH}_{3}\right)$; EIMS (m/z) 134 (63), 120 (10), 119 (100), 117 (21), 106 (9), 105 (23), 103 (11), 93 (14), 92 (20), 91 (91), 79 (24), 78 (11), 77 (33), 65 (15), 55 (11), 53 (9), 51 (9), 41 (15), 39 (15).

(3E,5E)-2-Methoxy-2,6-dimethyl-3,5,7-octatriene (14). Yield: $117 \mathrm{mg}(60 \%)$. (3E,5E)-14 (85 $\%)$ and (3E,5Z)-14 (15\%) according to NMR. (3E,5E)-14: ${ }^{1} \mathrm{H}$ NMR $\left(\mathrm{CDCl}_{3}, 400 \mathrm{MHz}\right) \delta \mathrm{ppm}$ $6.41\left(\mathrm{dd}, 1 \mathrm{H}, J_{4,5}=11.18 \mathrm{~Hz}, J_{4,3}=15.59 \mathrm{~Hz}, \mathrm{H}-4\right), 6.33\left(\mathrm{dd}, 1 \mathrm{H}, J_{7,8 a}=17.24 \mathrm{~Hz}, J_{7,8 b}=11.18\right.$ Hz, H-7), 6.01 (d, 1H, H-5), 5.66 (d, 1H, H-3), 5.15 (d, 1H, H-8a), 4.98 (d, 1H, H-8b), 3.10 (s, $\left.3 \mathrm{H}, \mathrm{O}-\mathrm{CH}_{3}\right), 1.81\left(\mathrm{~s}, 3 \mathrm{H}, \mathrm{C} 6-\mathrm{CH}_{3}\right), 1.24\left(\mathrm{~s}, 6 \mathrm{H}, \mathrm{C} 2-\left(\mathrm{CH}_{3}\right)_{2}\right) ;{ }^{13} \mathrm{C} \mathrm{NMR}\left(\mathrm{CDCl}_{3}, 100 \mathrm{MHz}\right) \delta$ (ppm) 141.54 (C-3), 140.32 (7), 135.70 (C6), 131,18 (C5), 125.97 (C-4), 113.07 (C-8), 75.51 (C2), $50.85\left(\mathrm{O}-\mathrm{CH}_{3}\right), 26.31\left(\mathrm{C} 2-\left(\mathrm{CH}_{3}\right)_{2}\right), 12.45\left(\mathrm{C} 6-\mathrm{CH}_{3}\right) ; \mathrm{EIMS}(\mathrm{m} / \mathrm{z}) 166(68), 165$ (11), 152 (7), 151 (82), 150 (15), 137 (13), 136 (12), 135 (35), 133 (26), 123 (18), 119 (100), 118 (14), 117 (24), 109 (10), 107 (35), 105 (33), 93 (46), 92 (22), 91 (79), 90 (21), 86 (25), 85 (11), 79 (28), 76 (54), 73 (17), 67 (6), 65 (11), 59 (64), 58 (25), 55 (13), 43 (46).

(3Z/5E)-2-Ethoxy-2,6-dimethylocta-3,5,7-triene (15). ${ }^{1} \mathrm{H} \mathrm{NMR}\left(\mathrm{CDCl}_{3}, 400 \mathrm{MHz}\right) \delta 6.49$ (dd, $\left.1 \mathrm{H}, J_{7,8 a}=17.1 \mathrm{~Hz}, J_{7,8 b}=11.0 \mathrm{~Hz}, \mathrm{H}-7\right), 6.40\left(\mathrm{ddd}, 1 \mathrm{H}, \mathrm{J}_{3,4}=17,3 \mathrm{~Hz}, \mathrm{H}-7\right), 6.10\left(\mathrm{~d}, 1 \mathrm{H}, J_{4,5}=\right.$ $10.4 \mathrm{~Hz}, \mathrm{H}-5), 5.78$ (d, 1H, J $\left.\mathrm{J}_{3,4}=15,4 \mathrm{~Hz}, \mathrm{H}-3\right), 5.24$ (d, 1H, $\left.J_{7,8 a}=17.1 \mathrm{~Hz}, \mathrm{H}-8 \mathrm{a}\right), 5.07(\mathrm{~d}, 1 \mathrm{H}$, $\left.J_{7,8 a}=11 \mathrm{~Hz}, \mathrm{H}-8 \mathrm{~b}\right), 3.35\left(\mathrm{q}, 2 \mathrm{H}, \mathrm{OCH}_{2} \mathrm{CH}_{3}\right), 1.90\left(\mathrm{~s}, 3 \mathrm{H}, \mathrm{CH}_{3}\right), 1.34\left(\mathrm{~d}, 6 \mathrm{H}, \mathrm{CH}_{3}\right), 1.18(\mathrm{t}, 3 \mathrm{H}$, $\left.\mathrm{CH}_{2} \mathrm{CH}_{3}\right) ;{ }^{13} \mathrm{C}$ NMR $\left(\mathrm{CDCl}_{3}, 100 \mathrm{MHz}\right) \delta 141.8$ (C-3), 140.8 (C-7), 135.1 (C-6), $130.9(\mathrm{C}-5)$, 125.6 (C-4), 112.5 (C-8), 74.9 (C-2), 58.0 (C-1'), 26.5 (2 x C-2 CH$), 16.1\left(\mathrm{C}-6 \mathrm{CH}_{3}\right), 12.0(\mathrm{C}-$ 2'); EIMS (m/z) $180\left(\mathrm{M}^{+\bullet}, 54\right), 165$ (66), 151 (19), 136 (51) 135 (52), 121 (31), 119 (72), 109 
(61), 107 (68), 105 (40), 93 (100), 91 (95), 79 (41), 77 (60), 59 (44), 55 (34). EI-HRMS calcd. for $\mathrm{C}_{12} \mathrm{H}_{20} \mathrm{O} 180.15142$, found 180.15157 .

(3Z/5E)-2-Isopropxy-2,6-dimethylocta-3,5-diene (16). ${ }^{1} \mathrm{H} \mathrm{NMR}\left(\mathrm{CDCl}_{3}, 400 \mathrm{MHz}\right) \delta 6.38$ (dd, $\left.1 \mathrm{H}, J_{7,8 a}=17.1 \mathrm{~Hz}, J_{7,8 b}=11.0 \mathrm{~Hz}, \mathrm{H}-7\right), 6.34\left(\mathrm{dd}, 1 \mathrm{H}, J_{3,4}=17,3 \mathrm{~Hz}, \mathrm{H}-4\right), 6.01\left(\mathrm{~d}, 1 \mathrm{H}, J_{4,5}=\right.$ $11.0 \mathrm{~Hz}, \mathrm{H}-5), 5.72$ (d, 1H, J $\left.\mathrm{J}_{3,4}=15,4 \mathrm{~Hz}, \mathrm{H}-3\right), 5.20$ (d, 1H, J J,8a $\left.=17.1 \mathrm{~Hz}, \mathrm{H}-8 \mathrm{a}\right), 4.98(\mathrm{~d}, 1 \mathrm{H}$, $\left.J_{7,8 a}=11 \mathrm{~Hz}, \mathrm{H}-8 \mathrm{~b}\right), 3.60$ (sept., $\left.1 \mathrm{H}, \mathrm{OCH}\left(\mathrm{CH}_{3}\right)_{2}\right), 1.71\left(\mathrm{~s}, 3 \mathrm{H}, \mathrm{CH}_{3}\right), 1.22\left(\mathrm{~d}, 6 \mathrm{H}, \mathrm{CH}_{3}\right), 1.18$ (d, $\left.6 \mathrm{H},-\mathrm{CH}\left(\mathrm{CH}_{3}\right)_{2}\right) .{ }^{13} \mathrm{C} \mathrm{NMR}\left(\mathrm{CDCl}_{3}, 100 \mathrm{MHz}\right) \delta 141.2(\mathrm{C}-3), 140.3(\mathrm{C}-7), 135.1$ (C-6), 131.0 (C-5), 124.8 (C-4), 112.6 (C-8), 75.4 (C-2), 64.8 (C-1'), 27.1 (2 x C-2 CH3), 25.0 (2 x C-2'), $12.1\left(\mathrm{C}-6 \mathrm{CH}_{3}\right)$; EI-MS (m/z) $194\left(\mathrm{M}^{+\bullet}, 16\right), 179$ (6), 152 (13), 151 (15), 137 (25) 135 (24), 119 (22) 109 (100), 107 (31), 93 (56), 91 (46), 81 (27), 77 (30), 67 (14), 55 (12). EI-HRMS calcd. for $\mathrm{C}_{13} \mathrm{H}_{22} \mathrm{O}$ 194.16707, found 194.16813.

Dehydrogenation of ocimene with DDQ. Ocimene (40 mg, $0.3 \mathrm{mmol}$, mixture of $3 E, 3 Z$ isomers) was dissolved in carbon tetrachloride $(15 \mathrm{ml})$ and DDQ $(0.20 \mathrm{~g}, 0.9 \mathrm{mmol})$ was added with stirring. Stirring was continued for $48 \mathrm{~h}$ under argon at room temperature. After $48 \mathrm{~h}$ GCMS revealed the exclusive formation of 5. Owing to the absence of water no concomitant formation of the alcohol 6 was observed.

\section{Acknowledgements}

Rearing of plant and insect cultures by Angelika Berg is gratefully acknowledged. We thank the Fonds der Chemischen Industrie, Frankfurt a. M., for financial support. 


\section{References}

1. Ozawa, R.; Arimura, G.; Takabayashi, J.; Shimoda, T.; Nishioka, T. Plant Cell Physiol. 2000, 41, 391.

2. Koch, T.; Krumm, T.; Jung, V.; Engelberth, J.; Boland, W. Plant Physiol. 1999, 121, 153.

3. De Moraes, C. M.; Lewis, J. M.; Paré, P. W.; Alborn, H. T.; Tumlinson, J. H. Nature 1998, 393, 570.

4. Gouinguene, S.; Alborn, H.; Turlings, T. C. J. J Chem Ecol 2003, 29, 145.

5. Donath, J.; Boland, W. Phytochemistry 1995, 39, 785.

6. Arthur, C. L.; Pawliszyn, J. Analytical Chemistry 1990, 62, 2145.

7. Dicke, M.; Gols, R.; Ludeking, D.; Posthumus, M.A. J. Chem. Ecol. 1999, 25, 1907

8. Kaiser, R.; Lamparsky, D. Parf. Cosm. Arômes 1977, 17, 71-79.

9. Brunke, E. J.; Hammerschmidt, F. J.; Schmaus, G. ACS Symp. Ser. 1993, 525, 282.

10. Rodriguez-Reinoso, F. Carbon 1998, 36, 159.

11. Coughlin, R. W. Ind. Eng. Chem. Prod. Res. Dev. 1969, 8, 12.

12. Yang, K.; Johnson, M. A. J. Org. Chem. 1977, 42, 3754.

13. Makino, B.; Kawai, M.; Yamamoto, T.; Yamamura, H.; Butsugan, Y.; Hayashi, M.; Ogawa, K. J. Chem. Soc., Chem. Commun. 1992, 1430.

14. Tomita, A.; Mori, S.; Tamai, Y. Carbon 1971, 9, 224.

15. Zacharia, R. Ph.D., Freie Universität Berlin, 2004.

16. Zhu, Z. H.; Finnerty, J.; Lu, G. Q.; Yang, R. T. Energy Fuels 2002, 16, 1359.

17. Braude, E. A.; Jackman, L. M.; Linstead, R. P.; Lowe, G. J. Chem. Soc. 1960, 3133.

18. van Dort, H. M.; Jagers, P. P.; Terheide, R.; Vanderweerdt, A. J. A. J. Agric. Food Chem. 1993, 41, 2063. 